IdeAs

Idées d'Amériques

$8 \mid 2016$

Ressources minières dans les Amériques: Mutations

d'un continent

\title{
Recursos minerais nas Américas. Mutações de um continente
}

Mineral resources in the Americas - a continent under mutation

Ressources minières dans les Amériques: Mutations d'un continent

Susanne Berthier-Foglar, Franck Gaudichaud e Sandrine Tolazzi

\section{(2) OpenEdition}

Journals

\section{Edição electrónica}

URL: https://journals.openedition.org/ideas/4709

DOI: 10.4000/ideas.4709

ISSN: 1950-5701

Este artigo é uma tradução de:

Ressources minières dans les Amériques: Mutations d'un continent - URL : https:// journals.openedition.org/ideas/1636 [fr]

Outra(s) tradução(ões) deste artigo:

Mineral resources in the Americas - a continent under mutation - URL : https:// journals.openedition.org/ideas/2268 [en]

Recursos mineros en las Américas : mutaciones de un continente - URL : https:// journals.openedition.org/ideas/3096 [es]

Editora

Institut des Amériques

\section{Refêrencia eletrónica}

Susanne Berthier-Foglar, Franck Gaudichaud e Sandrine Tolazzi, «Recursos minerais nas Américas. Mutações de um continente», IdeAs [Online], 8 | 2016, posto online no dia 20 dezembro 2018,

consultado o 18 outubro 2022. URL: http://journals.openedition.org/ideas/4709 ; DOI: https://doi.org/ $10.4000 /$ ideas. 4709

Este documento foi criado de forma automática no dia 18 outubro 2022.

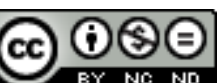

Creative Commons - Atribuição-NãoComercial-SemDerivações 4.0 Internacional - CC BY-NC-ND 4.0 https://creativecommons.org/licenses/by-nc-nd/4.0/ 


\title{
Recursos minerais nas Américas. Mutações de um continente
}

\author{
Mineral resources in the Americas - a continent under mutation \\ Ressources minières dans les Amériques: Mutations d'un continent
}

Susanne Berthier-Foglar, Franck Gaudichaud e Sandrine Tolazzi

Num contexto em que o aquecimento climático, mesmo que represente uma séria ameaça global, não consegue realmente reduzir o consumismo e a luta acirrada para a energia, que são em grande parte o nó górdio desses problemas climáticos, a questão do desenvolvimento de recursos minerais e da energia surge com muita acuidade, tanto mais que sua produção tem aumentado significativamente nas Américas, como no resto do mundo. Nos últimos anos, o "boom" do extrativismo, uma atividade humana que pode alterar significativamente o ambiente e o clima, pode ser considerado como parte de um conjunto de fatores que marcam uma nova era geológica, iniciada na virada do século XIX e cunhada "antropoceno" pelo Prêmio Nobel Paul Crutzen. Ao atribuir uma origem humana às transformações do clima ou do ambiente, os pesquisadores que defendem a tese do antropoceno, como Christophe Bonneuil e Jean-Baptiste Fressoz em seu livro L'Événément anthropocène (Paris: Seuil, 2013), convidam a uma tomada de consciência do impacto destas atividades sobre mudanças globais, as quais deixam pensar que talvez cheguemos a um ponto sem volta. Embora alguns membros da comunidade científica ainda se recusem a atribuir uma origem antropogênica a estas alterações (Samuele Furfari em Sandrine Tolazzi "Recursos minerais e energéticos: o choque dos discursos"), a grande maioria deles realça a necessidade de vincular de forma mais geral a questão das consequências ambientais àquela da exploração dos recursos (Normand Mousseau, no mesmo artigo). É verdade, além disso, que a questão ambiental se encontra muitas vezes no centro dos debates atuais sobre o desenvolvimento de recursos minerais. Também parece que o impacto econômico, político, geoestratégico e social do recente boom da mineração nas Américas implica mudanças reais em todo o continente, como destacado na entrevista com Bernadette Mérenne-Schoumaker. Portanto, é, acima de tudo, para tentar determinar a natureza destas mudanças que os coordenadores deste número, num primeiro momento, 
organizaram um colóquio internacional sobre a questão dos recursos de mineração nas Américas (Grenoble, junho de 2014). Posteriormente, chamaram alguns participantes do simpósio, assim como outros autores, para construir um dossiê que eles esperam ser representativo de interrogações científicas atuais. Na leitura de todos os artigos assim como das entrevistas, vemos áreas de tensão relacionadas com lutas de poder entre diferentes atores (comunidades locais, empresas, governos em diferentes níveis, etc.), mas também com representações destes jogos de poder ligadas à história do desenvolvimento da mineração.

2 A questão da mineração - e de forma mais ampla dos recursos naturais - está no centro de grandes convulsões geopolíticas e da redefinição assimétrica das relações Norte-Sul: a apropriação, a extração e o controle da riqueza através desta atividade têm sido poderosos motores do processo colonial e da expansão territorial experimentada pelas Américas a partir dos séculos XV-XVI. A "sede" de ouro e prata alimentou uma longa experiência de dominação ecossocial, política e cultural, além mesmo da Independência, forjando até hoje uma "tradição" de tipo colonial de exploração dos recursos por meio da qual as economias latino-americanas dependem de grandes potências industriais que dominam o sistema internacional (ver "Dominação e extroversão da América Latina”, em Géopolitique des Amériques, dir. Alain Musset, Paris : Nathan, 2014, $4^{\mathrm{e}}$ ed.). Este modelo impere entre o norte e o sul do continente, mas também nas relações da América Latina com outros pólos da economia mundial (Europa, China), e mesmo internamente, em cada país, tanto no sul como no norte do continente. Assim, Lucie Genay ( "A mineração de urânio no Novo México: um símbolo da conquista pelo átomo") mostra algo que a história da mineração de urânio no novo México confirma: embora os desafios enfrentados pelo setor da mineração tenham mudado, alguns padrões neo-coloniais de construção da nação estadunidense permaneceram e estão perpetuando um legado de desigualdade social e racial, gerando reações contrastantes por parte das nações indígenas. Este "neocolonialismo extrativista" também é fortemente denunciado por muitos movimentos socioambientais e por comunidades indígenas na América Latina, e tais mobilizações são a fonte de vários conflitos tanto com os governos quanto com as mineradoras. Com a proliferação dessas mobilizações, os executivos do continente elaboram uma série de estratégias, que vão da repressão ou da contenção institucional até moratórias e a declarações estabalecendo aréas de mineração livre em partes do território nacional (Maria Teresa Gutierrez-Haces, "O investimento estrangeiro e a atividade de mineração na América Latina. As estratégias governamentais em conflitos com as empresas de mineração"). Pois, este governos bem podiam se rotular como progressivistas, "nacionais-populares" ou conservadores; mas todos eles tentaram usar o "boom" dos preços das matérias-primas e de mineração nos últimos anos, embora de acordo com lógicas diferentes em termos de política pública. No entanto, a crise global e a queda na demanda desde 2007-2008 sublinharam o fato de que as economias da América podem se inscrever fortemente numa lógica de renda e de reprimarização contrária a qualquer perspectiva de desenvolvimento "sustentável" ou virtuoso. Outro modelo de mineração é possível? Isto é sugerido pelo governo bolivariano da Venezuela com o seu "Plano de Ação Estratégico Comum para o Desenvolvimento da Faixa do Rio Orinoco e da mineração Arc", que pretende articular o crescimento econômico, a aliança com empresas multinacionais e o desenvolvimento dos serviços sociais públicos, tendo um controle, ao mesmo tempo, sobre a evolução das linhas pioneiras de mineração. No entanto, o estudo de Anne Péné-Annette sobre a mineração de ouro no estado "Bolívar" 
("O renascimento da mineração na Guiana venezuelana? ") recorda a amplitude da "destruição ambiental e dos danos humanos" que este extrativismo, levado a cabo num país inteiro, pode significar.

3 Doravante, muitos pesquisadores e ativistas não só oferecem análises críticas dessas formas de exploração industrial da natureza, mas também desvelam a existência de modelos alternativos de relação entre a natureza, a sociedade e a economia, ou ainda entre o norte e o sul (Sandrine Tolazzi, "Recursos minerais e energéticos: o choque dos discursos" e o artigo de Maristella Svampa assim como o trabalho de Anna Bednik citados em Franck Gaudichaud, "Recursos minerais, 'extrativismo' e desenvolvimento na América Latina: perspectivas críticas"). Como no Equador, onde o conceito de boas maneiras (Sumak Kawsay quechua), junto com a ideia de deixar os minerais e o petróleo na terra (particularmente em áreas de alta biodiversidade), começam a ganhar terreno na sociedade civil e no campo político, sem que seja resolvida a tensão problemática entre a proteção dos ecossistemas, o respeito às comunidades e o acesso a um padrão de vida para todos. Assim, na Bolívia de Evo Morales, se o imaginário do "Buen Vivir" continua a ser uma referência simbólica no discurso do presidente, o país segue estando dependente da exploração de recursos minerais e gasosos, cujo desenvolvimento atual está submetido às pressõs exercidas por diferentes organizações corporativistas, muito mais ainda do que à reconquista da soberania nacional (Claude Le Gouill, "Neodesenvolvimentismo, 'bom viver' e as lutas corporativas na política de mineração do governo de Evo Morales, na Bolívia").

4 A questão ambiental também faz parte de uma história de desenvolvimento da mineração, que, de acordo com Michel Deshaies, sempre teve um caráter "predador" para o ambiente ("Mineração e Meio Ambiente nas Américas: os paradoxos da mineração"). É verdade que, em grande medida, desapareceram os pequenos garimpeiros e as empresas de mineração sem restrições, que usam recursos com vista na rentabilidade imediata e, em seguida, abandonam terras altamente poluídas... Foram substituidos pelas grandes mineradoras cuja atividade está agora melhor emoldurada. Além disso, a pressão de algumas comunidades locais e de ONGs tem forçado as empresas a reduzir o seu impacto ambiental e a serem mais envolvidas com o desenvolvimento dos territórios, a fim de aumentar a sua "aceitação" e tentar reverter a imagem negativa que elas podem projetar. Deshaies, desta forma, nota que as grandes mineradoras enfrentam uma crescente oposição, por causa do impacto ambiental de suas atividades, mesmo que, paradoxalmente, este efeito nunca tenha se reduzido tanto. Porém, as grandes escalas dos projetos de mineração atualmente em desenvolvimento fazem com que este impacto, mesmo reduzido, seja muito significativo. Além disso, é preciso tomar em conta os problemas relacionados com a reabilitação dos territórios, uma vez que acabou sua exploração, ou com o risco de desastres acidentais (isto se viu recentemente, e de forma dramática, com a catástrofe mineira de Mariana, no Estado brasileiro de Minas Gerais).

5 O debate é portanto intenso sobre as consequências ambientais de megaprojetos de mineração, e os governos são induzidos a tomar mais cuidado, por meio de estudos, tais como a avaliação ambiental estratégica de gás de xisto encomendada pelo governo de Quebec, e da qual participaram Christiane Gagnon e Majella-J Gauthier ( "Inventário e vulnerabilidade das terras baixas do St. Lawrence (Quebec, Canadá) a exploração de gás de xisto"). 0 trabalho que seu estudo apresenta permitiu a identificação das áreas de vulnerabilidade, que deveria levar a uma melhor gestão da terra para futuros projetos 
de desenvolvimento em Quebec. No entanto, continua sendo difícil para os cientistas posicionar-se fora de qualquer retórica comum sobre tais questões. Na verdade, pode-se distinguir claramente uma retórica projetada para minimizar o impacto de grandes projetos de desenvolvimento, ou para apresentá-los como ambientalmente benéficos. Assim, não só Samuele Furfari afirma que "a energia fóssil, apesar de seu impacto ambiental, tem tido repercussões extraordinariamente positivas sobre nossas condições de trabalho, de vida e saúde", mas também apresenta o desenvolvimento do gás de xisto como uma solução para reduzir os efeitos de gases de efeito estufa (Sandrine Tolazzi, "Recursos minerais e energéticos: o choque dos discursos"). Nessa ótica, os opositores do desenvolvimento de gás de xisto são apresentados como mal informados sobre o processo de exploração e extração (RTI Internacional, no mesmo artigo). Por outro lado, pode-se destacar um discurso que indique claramente o impacto ambiental do desenvolvimento de recursos minerais e o apresenta como um dos principais desafios no desenvolvimento de uma estratégia global de recursos minerais (Normand Mousseau, no mesmo artigo). Se trata então de saber se é melhor empenhar-se em reduzir o impacto ambiental dos projetos de mineração ou se é necessáio abolir pura e simplesmente eesses projetos, a fim de favorecer uma verdadeira transição ecológica.

Além disso, a exploração de recursos mobiliza cada vez mais atores locais que tomam consciência de sua condição de minorias exploradas ou sacrificadas. Depósitos são explorados em zonas de montanha, que eram historicamente o refúgio dos pobres, em sua maioria indígena, e pouco a pouco as populações adquiriram a consciência de que, já há bastante tempo, foram roubadas. As etnias locais, então, têm uma nova visibilidade na política, quando elas se opõem à decisão de um Estado que parece defender os interesses de outros grupo sociais e culturais. Na América Latina, observamos o ressurgimento de identidades étnicas antigas, que tenderam a ser abafadas num contexto de assimilação e de menosprezo dos "índios", um termo que, em Espanhol (Indio), muitas vezes, se assemelha a um insulto. Há quinze anos que as comunidades camponesas, que são, por vezes, de indígenas, com o significado da Declaração de Direitos dos Povos Indígenas das Nações Unidas, resistem fortemente aos projetos de mineração e exigem das empresas de mineração um melhor aproveitamento para as terras locais, assim como uma participação dos benefícios. 0 artigo de Carmen Salazar-Soler ("O papel da etnicidade nos conflitos da mineração socioambiental nos Andes do Peru, XX-XXI séculos") ilumina essa tomada de consciência e as demandas dos povos indígenas a favor de um controle eficaz de poluição e para ter uma voz nas decisões no que diz respeito à exploração e à utilização dos recursos naturais em seus territórios.

7 Para Lucie Genay ("A mineração de urânio no Novo México, um símbolo da conquista pelo átomo"), a mineração em terras indígenas e hispânicas no Novo México se assemelha tanto à conquista quanto à colonização. A autora destaca a vulnerabilidade dos habitantes de regiões mineradoras cuja economia está enfraquecida pela natureza cíclica da exploração destes recursos. De um ponto de vista social, ela também observa a persistência de todo um "legado" de dependência e de desigualdade, apesar de uma militância forte, mas sem coesão centralizadora, nas regiões onde estão localizados os depósitos de urânio.

o eco-ativismo está enraizado no oeste americano onde se origina nos movimentos de preservação da natureza e de criação dos primeiros parques nacionais no final do século XIX. Esta tradição de uma certa visão da natureza se reflete na oposição 
militante à mineração. Um lugar com um perfil ambiental forte, seja ele um parque nacional ou outra área protegida ou uma montanha sagrada, conglomera as oposições à mineração. Isto é particularmente evidente nas opiniões muito marcadas das tribos / nações Navajo e Laguna (Susanne Berthier-Foglar, "A exploração dos recursos minerais do Oeste americano” e Lucie Genay “, A mineração de urânio no Novo-México “).

Ultrapassando o quadro americano, as organizações militantes com apelo internacional se mostram atentas às situações de espoliação dos povos oprimidos do mundo. Longe do contexto social e econômico, essas posições nem sempre têm um grande efeito, mas têm o mérito de alertar a opinião pública. De qualquer forma, nos países em causa, é evidente que as razões econômicas ou militares têm a primazia sobre a proteção da natureza. Graças ao artigo de Susanne Berthier-Foglar ("Recursos minerais e energéticos: A evolução e os desafios constantes") constatamos como era possível, para os proprietários de uma mina de urânio no coração do parque nacional do Grand Canyon, de fazer com que seja aceito uma exploração intrusiva na borda de um penhasco, apenas a cem metros de um sítio turístico. Durante a Guerra Fria, os desafios da defesa nacional, com a corrida pela elaboração de armas atômicas, pareciam mais importante do que a integridade do parque.

Assim, a questão da exploração dos recursos minerais e energéticos é fundamental para a compreensão de alguns modelos econômicos de desenvolvimento, mas também das relações de poder que estão em jogo. É fascinante, para os investigadores que analisam estas questões, ver que a mineração tem impacto econômico, social e ambiental em todas as escalas, do local ao global, e desde o indivíduo - como pode ser visto através das fotografias de Louie Palu (entrevista com Lucie Genay) - até a comunidade, sem esquecer também o governo e a indústria. É, portanto, uma questão verdadeiramente estratégica nas Américas, e os artigos deste dossiê apresentam alguns aspectos deste vasto campo de investigação.

\section{AUTORES}

\section{SUSANNE BERTHIER-FOGLAR}

Susanne Berthier-Foglar est professeur, spécialiste de l'Ouest américain et des peuples autochtones, Université Grenoble Alpes (ILCEA4).susanne.berthier@univ-grenoble-alpes.fr

\section{FRANCK GAUDICHAUD}

Franck Gaudichaud est maître de conférences en histoire et civilisation de l'Amérique Latine à l'Université Grenoble Alpes et membre de l'ILCEA4 (EA 7356). franck.gaudichaud@univ-grenoblealpes.fr

\section{SANDRINE TOLAZZI}

Sandrine Tolazzi est maître de conférences à l'Université Grenoble Alpes (UFR des Langues, ILCEA4 - Institut des Langues et des Cultures d'Europe, Amérique, Afrique, Asie et Australie). sandrine.tolazzi@univ-grenoble-alpes.fr 